Check for updates

Cite this: RSC Adv., 2019, 9, 19508

\title{
Effect of poly-methyltriethoxysilane on the waterproof property of starch/fiber composites with open cell structures
}

\author{
Xu Sun, ${ }^{\text {ab }}$ Xiu-jie Jia, (D) *ab Fang-yi Li, (DD ab Jian-feng Li, ${ }^{\text {ab }}$ Jian-yong Li, ${ }^{\text {ab }}$ \\ Chuan-wei Zhang, ${ }^{\text {ab }}$ Shuai Chen, ${ }^{\text {ab }}$ Jin-feng Cui, ${ }^{\text {ab }}$ Kai-qiang Sun ${ }^{\text {ab }}$ \\ and Shan-guo Zhang ${ }^{\text {ab }}$
}

Novel starch/fiber composites with open cell structures were proposed through thermo-cavity molding. To overcome the disadvantage of the water sensitivity of the resulting composites, poly-methyltriethoxysilane (PTS) was added as a waterproofing agent. The results showed that the addition of PTS improved the waterproof property of the composites. The composites with $15 \mathrm{~g}$ PTS (PTS-15) exhibited an optimal waterproof property. The water contact angle and drop absorption of the PTS-15 composites improved by $59.9 \%$ and $223.5 \%$, respectively, compared with the values for those without PTS. Moreover, the addition of PTS could effectively prevent the degradation of the mechanical properties of the composites after water absorption. The rate of tensile property degradation for the PTS-15 composites reached $5.3 \%$, whereas that for the PTS-0 composites totaled 56.6\%. The chemical bonds and micro-structure of the composites were investigated to reveal the inherent mechanism of property changes. Fourier transform infrared spectra revealed the formation of new hydrogen bonds between starch and PTS. Hydrophobic groups, including $\mathrm{Si}-\mathrm{O}-\mathrm{Si}, \mathrm{Si}-\mathrm{C}$, and $\mathrm{Si}-\mathrm{OH}$, were found in the resulting composites, thereby explaining the waterproof property changes. Scanning electron microscopy images showed that the open cell structure of the composites initially became denser and then loosened with the increase in the PTS content, resulting in the initial enhancement and the subsequent weakening of their mechanical properties.

Received 30th April 2019 Accepted 4th June 2019 DOI: 10.1039/c9ra03221e rsc.li/rsc-advances

\section{Introduction}

At present, with the rapid development of express packaging industries, the problems including environmental pollution and non-renewable resource consumption caused by plastic packing materials have become prevailing concerns among environmental science communities. ${ }^{1-3}$ To solve these issues, scholars have focused on identifying biodegradable composites prepared using renewable natural polymers (e.g., starch, fiber, lignin, polylactic acid (PLA), poly- $\beta$-hydroxybutyrate (PHB), and chitosan)., In particular, plant fiber and starch, as the most abundant organic compounds found in nature, are ideal materials for the preparation of biomass composites. However, the natural starchbased composites feature poor mechanical properties given their high hydrophilicity and crystallinity. ${ }^{6}$ Several strategies have been investigated to minimize or overcome these poor characteristics; these strategies include blending thermoplastic starch (TPS) with different biodegradable polymers such as polyvinyl alcohol

${ }^{a}$ Key Laboratory of High Efficiency and Clean Mechanical Manufacture (Ministry of Education), School of Mechanical Engineering, Shandong University, Jinan 250061, China.E-mail: xjjia@sdu.edu.cn; ljy@sdu.edu.cn

${ }^{b}$ National Demonstration Center for Experimental Mechanical Engineering Education, Shandong University, Jinan 250061, China
(PVA), ${ }^{7}$ polycaprolactone ${ }^{8}$ polylactic acid, ${ }^{9}$ cellulose fibers ${ }^{10}$ or plant fibers. ${ }^{11}$

In addition, scholars have focused on the research of starch modification methods, including esterification, ${ }^{12}$ etherification, ${ }^{13}$ oxidation, ${ }^{6,14}$ graft-copolymerization, ${ }^{15}$ and plasticization. ${ }^{6,16}$ Zhang $^{17,18}$ investigated a starch modification method combining oxidation and plasticization. This method can form additional hydrogen bonds between TPOS and the sisal fiber, thereby improving the mechanical properties of the composites but reducing their waterproof property. The effects of citric acid on the properties of glycerol-plasticized thermoplastic starch (GPTPS) were studied by Yu J. G. ${ }^{19}$ Citric acid can also improve the elongation of GPTPS and ameliorate its water resistance at high relative humidity (RH). However, citric acid decreases the tensile stress. Cova A. ${ }^{20}$ obtained modified cassava derivatives by modifying the native cassava starch (CS) with octenyl succinic anhydride (OSA). The results showed that OSA modification yielded a more hydrophobic material than native CS. Ma $\mathrm{X} .{ }^{21}$ prepared pea starch-based composites reinforced with citric acid-modified pea starch (CAPS) and citric acid-modified rice starch (CARS) by screw extrusion. The introduction of granular CAPS and CARS improved the storage modulus, glass transition temperature, tensile strength, and water vapor barrier properties of the composites but decreased their thermal stability. The 
results showed the complex preparation technology, which cannot simultaneously satisfy the mechanical and waterproof properties of the composites.

Starch and fiber, as the main components of starch-based biomass composites, are hydrophilic polymers. Therefore, the waterproof property of starch-based biomass composites is seriously inadequate. Specific methods are necessary to improve this characteristic. Wang ${ }^{22}$ suggested that the hydrophobic surface with an oligosilazane coating inhibits water absorption, showing potential for application as a waterproof surface coating for electromagnetic wave-transmitting materials. Han $Y .{ }^{23}$ prepared trays using a starch foam reinforced with an aspen wood fiber. The tray surface was treated with $\mathrm{CF}_{4}$ and $\mathrm{SF}_{6}$ plasma to obtain hydrophobic properties. Lee ${ }^{24}$ proposed a medical dressing using the polydimethylsiloxane (PDMS) membrane. The non-porous face of the PDMS film provided a natural waterproofing barrier against intrusion by microbes and contaminants. Gong ${ }^{25}$ indicated that blending an organosilicon hydrophobic agent with cement effectively improved the waterproof performance of a thermal insulation mortar. Lu X. ${ }^{26}$ observed that the textile treated with $\mathrm{VO}_{2} @ \mathrm{TiO}_{2}$ and $\mathrm{TiO}_{2}$ multi-scale hybrid particles showed hydrophobicity, self-cleaning properties, and improved durability. Scholars have shown that surface treatment with lowtemperature plasma can enhance the waterproof property of the composites but at an extremely high cost of commercialization. Organic silicon and other materials are widely used for waterproofing in the construction industry.

Starch modification can improve the mechanical properties of starch-fiber composites, but it reduces the waterproof property at the same time. Moreover, the preparation of composites by plasma surface treatment is expensive. Meanwhile, the inclusion of additives cannot evidently improve the waterproof property, and the additives are not environment friendly.

Based on these considerations, we prepared waterproof starch-based composites using plasticized and modified starch as the binder and poly-methyltriethoxysilane (PTS) as the waterproofing additive. Starch modification can destroy the internal crystalline structure of starch, thus increasing the number of free branched chains in the crystallization area and resulting in a better combination of starch and fiber. Such a combination can improve the mechanical properties of the starch-based composites. The addition of PTS can result in the formation of hydrophobic chemical bonds, namely, Si-O-Si, Si$\mathrm{C}$, and $\mathrm{C}-\mathrm{O}-\mathrm{Si}$ between starch and the PTS molecules, and these bonds can prevent the water molecules from passing through. Moreover, organosilicon is a green material that causes zero pollution to the environment.

\section{Experimental}

\subsection{Materials and equipment}

2.1.1 Materials. Sisal fibers with an average length of 5$10 \mathrm{~mm}$ were prepared. The length-to-diameter ratio of the sisal fibers was 120. Sweet potato starch (SPS) was purchased from Hebei Yanxing Chemical Industry Co. Ltd. (Hebei, China). Polymethyl triethoxy silane (PTS) was purchased from Xingfeilong Chemical Co. Ltd. (Jinan, China). Talcum powder as the

filling agent was purchased from Tianjin Fuyu Fine Chemical Co. Ltd. (Tianjin, China). Azodicarbonamide (AC) as the foaming agent (99\% purity) was obtained from Jinan New Weiye Co. Ltd. (Shandong, China). Polyvinyl alcohol (PVA) (99\% purity) was acquired from Jinan Yuxing Chemical Co. Ltd. (Shandong, China); $\mathrm{NaOH}$, distilled water, and other additives were purchased from Yantai Shuangshuang Chemical Co. Ltd. (Shandong, China).

The main experimental equipment in this paper is shown in Table 1.

\subsection{Preparation of starch-based composites}

2.2.1 Preparation of starch slurry. Starch slurries were prepared according to the following procedure: $150 \mathrm{~mL}$ distilled water was mixed with $50.0 \mathrm{~g}$ starch in a $500 \mathrm{~mL}$ round bottomed flask and then stirred with a glass bar for $5 \mathrm{~min}$. Glycerol and ethylene glycol as plasticizers were added to the mixture in the best ratio of $2: 1 .^{27}$ The mixture was heated for $30 \mathrm{~min}$ with stirring at $85{ }^{\circ} \mathrm{C}$. Subsequently, $10 \mathrm{~g}$ AC, $15 \mathrm{~g}$ PVA, and $30 \mathrm{~g}$ talcum powder were added into the flask. Different amounts of PTS (0 g, 5 g, $10 \mathrm{~g}, 15 \mathrm{~g}$, and $20 \mathrm{~g}$ ) were added into different flasks after $20 \mathrm{~min}$. Each group was labeled based on the mass of PTS: PTS-0, PTS-5, PTS-10, PTS-15, and PTS-20. A preliminary trial with the gradients of $2.5 \mathrm{~g}$ and $20 \mathrm{~g}$ was conducted before the experiment. The experimental results showed that when the gradient was $2.5 \mathrm{~g}$, the change in the waterproof property was negligible, whereas the slurry was difficult to form when the addition amount reached $40 \mathrm{~g}$. Therefore, we finally selected the experimental scheme with $5 \mathrm{~g}$ as the gradient.

2.2.2 Preparation of alkaline fibers. The sisal fibers were placed into the micro plant grinding machine for $5 \mathrm{~min}$, and 3$5 \mathrm{~mm}$ short sisal fibers were obtained. Subsequently, the short sisal fibers were placed in $\mathrm{NaOH}$ solution with a mass fraction of $5 \%$ for $5 \mathrm{~h}$ and then washed with distilled water until the $\mathrm{pH}$ was 7. Finally, the processed sisal fibers were placed in an electric thermostat blast drying oven for $12 \mathrm{~h}$ at a temperature of $100{ }^{\circ} \mathrm{C}$. Alkaline sisal fibers were then obtained.

2.2.3 Preparation of the composites. As shown in Fig. 1, the composite preparation is divided into four steps: fiber treatment, starch modification, slurry mixing, and thermo-cavity foam formation.

Table 1 Experimental equipment

Equipment

Hot-embossing machine with double column thermoforming mold

Electronic constant temperature water bath

Precision by force electric mixer

Electric thermostat blast drying oven

Graphite bent crystal monochromator

Nickel-copper filter radiator

FT-IR spectrometer

Electronic tensile machine

Carton compression testing machine

Scanning electron microscope

Contact angle instrument

Constant humidity testing machine
Specification

Custom-

made

HHS-2

$\mathrm{JJ}-1$

DHG

BDX2000

YS20B

TENSOR 37

XLW(L)-PC

XYD-15K

FEG250

XG-CAMB

RHP-800BT 


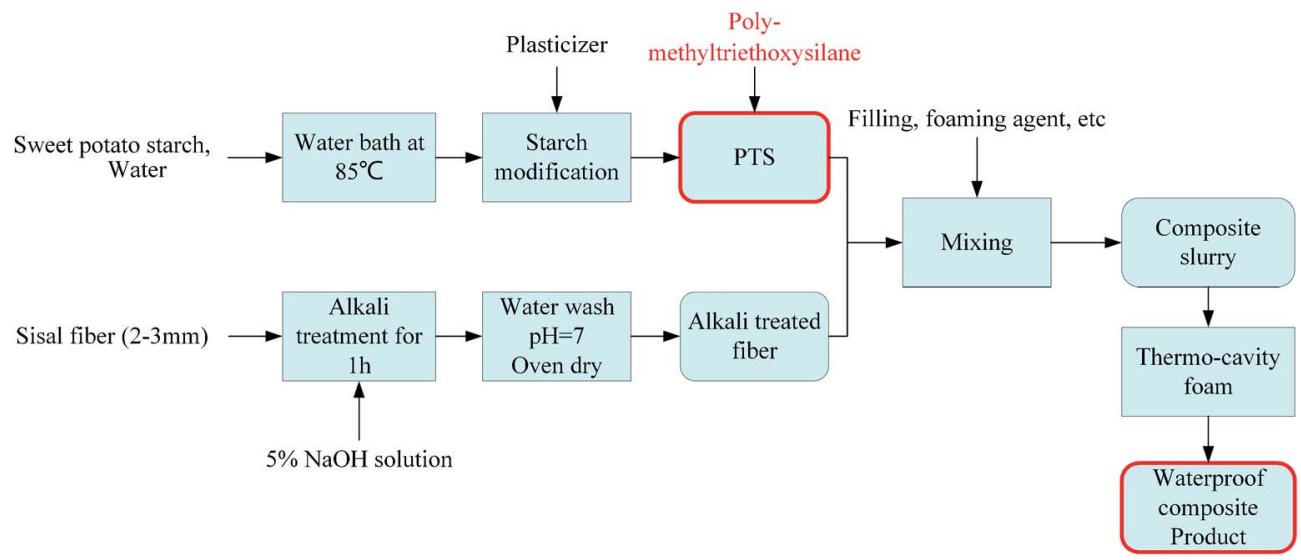

Fig. 1 Flow chart for the preparation of waterproof composites.

Starch modification and fiber treatment have been described in Sections 2.2.1 and 2.2.2, respectively. The third step involves slurry mixing. The modified starch and alkali-treated fiber were placed in a blender, and the other fillings were added and mixed for $20 \mathrm{~min}$. Finally, the composite slurry was injected into the cavity-foaming molding machine. The upper and lower molds were closed to shape the slurry. After $10 \mathrm{~s}$, the upper molds were raised to a certain height, leaving the foaming area above the slurry. Azodicarbonamide was used as the foaming agent. After decomposition of the internal foaming agent of the slurry, gas was released at $200{ }^{\circ} \mathrm{C}$ towards the foaming area. The foaming area pressure was controlled at $2.5-3.0 \mathrm{MPa}$ by a pressure transducer and gas metering valve, whereas the temperature was maintained from $195{ }^{\circ} \mathrm{C}$ to $20{ }^{\circ} \mathrm{C}$ by a temperature transducer and a heating plate. The upper and lower mold temperatures were set at $195{ }^{\circ} \mathrm{C}$ and $200{ }^{\circ} \mathrm{C}$, respectively. Finally, five groups of new starch-based composites were prepared by thermo-cavity foam molding after $10 \mathrm{~min}$. The group labels were the same as those in Section 2.2.1, that is, PTS-0, PTS-5, PTS-10, PTS-15, and PTS-20.

\subsection{Property tests of the waterproofing composites}

2.3.1 Water absorption. The waterproof property of the composites is generally characterized by water absorption. Samples with a typical size of $20 \mathrm{~mm} \times 20 \mathrm{~mm} \times 2 \mathrm{~mm}$ (length $\times$ width $\times$ height) were dried at $100{ }^{\circ} \mathrm{C}$ for $24 \mathrm{~h}$. After weighing $\left(W_{0}\right)$, the specimens were placed in the test machine at a constant temperature $\left(30{ }^{\circ} \mathrm{C}\right)$ and relative humidity $(\mathrm{RH})$ (65\%) for six days. The samples were collected every day and immediately weighed $\left(W_{1}\right)$. Then, the samples were returned inside the machine. The water absorption $\left(W_{\mathrm{s}}\right)$ of samples was calculated using the following equation: ${ }^{28}$

$$
W_{\mathrm{s}}=\frac{W_{1}-W_{0}}{W_{0}} \times 100 \%
$$

2.3.2 Water contact angles. The test samples $(20 \mathrm{~mm} \times$ $20 \mathrm{~mm} \times 5 \mathrm{~mm}$ ) were placed horizontally on the experiment platform of the contact angle measuring instrument. ${ }^{29}$ The baseline for testing the software interface is below the surface of the composite matrix. The knob above the needle was rotated to add $50 \mu \mathrm{L}$ distilled water every time. The value was tested and recorded with the software after stabilization. Every sample was tested thrice, and the experimental data were recorded. The final contact angle was considered as the average of three measurements.

2.3.3 Drop absorption time measurement. The test samples $(20 \mathrm{~mm} \times 20 \mathrm{~mm} \times 5 \mathrm{~mm})$ were placed horizontally on the experiment platform. A $50 \mu \mathrm{L}$ water droplet was placed on the wood surface with a special pipette. The water uptake time was measured when the droplet was placed onto the wood surface. This time interval covers the impact of the droplet until its complete penetration into the wood (no optical reflections were observed). In this analysis, a water drop was placed on the surface at nearly $100 \%$ saturated atmosphere to eliminate evaporation as a competing process. ${ }^{30}$

\subsection{Characterization of mechanical properties}

2.4.1 Experiments of compressive strength tests. The test samples $(100 \mathrm{~mm} \times 100 \mathrm{~mm} \times 25 \mathrm{~mm})$ were prepared in accordance with GB/T 8168-2008 China using the standard method A. A XYD-15K compression testing machine was preloaded with $5 \mathrm{kN}$ of the specimens with thickness that was regarded as the original thickness. The XYD-15K compression testing machine loaded the sample at $12 \mathrm{~mm} \mathrm{~min}^{-1}$ along the thickness and automatically recorded the load values. The compressive strength and strain were then calculated.

2.4.2 Tensile strength test. The test samples were prepared according to GB/T 9641-88 China. The tensile specimens were drawn using a smart electronic tensile tester at $25 \mathrm{~mm} \mathrm{~min}^{-1}$ for tensile strength testing.

All measurements were conducted on the five samples, and the maximum and minimum values were removed. The three remaining numbers were averaged (Fig. 2).

2.4.3 Cushion performance test. The data were obtained from the compressive strength test, and the stress-strain curve of the sample was plotted to calculate the increment in the unit volume of the sample under different stress conditions to obtain the compressive energy absorption efficiency. 

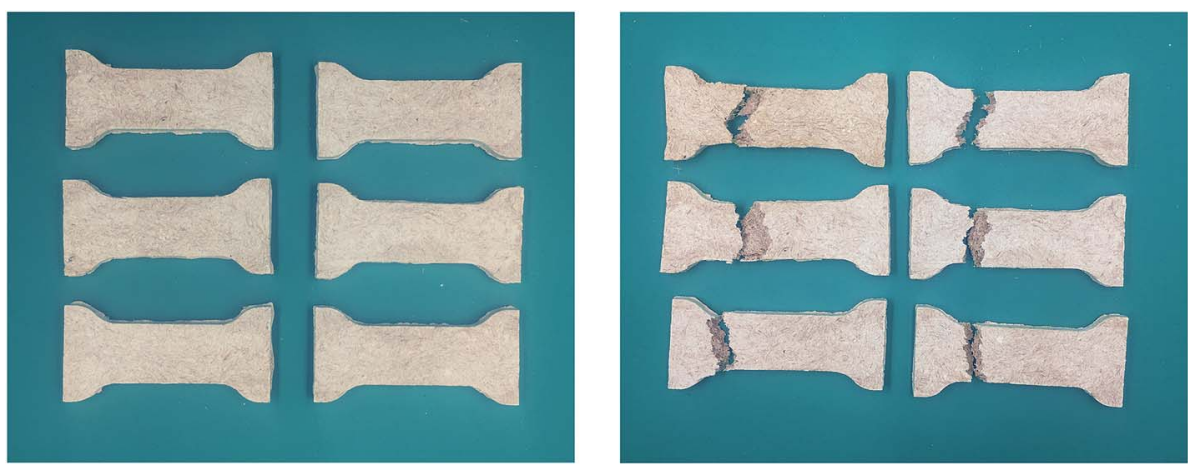

Fig. 2 Before and after drawing of the tensile strength test sample.

According to the above two formulas, a stress-strain curve was drawn by calculating the experimental data. The energy absorption efficiency-stress $(E-\sigma)$ curve was obtained through calculation.

The formula for compressive stress is

$$
\sigma=\frac{P}{A} \times 10^{6}
$$

where $\sigma$ is the compressive stress (Pa); $P$ is the compressive load $(\mathrm{N})$; and $A$ is the experimental sample bearing area $\left(\mathrm{mm}^{2}\right)$.

The formula for strain is

$$
\varepsilon=\frac{T_{\mathrm{j}}}{T} \times 100 \%
$$

where $\varepsilon$ is the compressive strain of the standard method $\mathrm{A}(\%)$, $T$ is the original thickness of the sample $(\mathrm{mm})$, and $T_{\mathrm{j}}$ is the thickness during the compressive stress test $(\mathrm{mm})$.

According to the above steps, a stress-strain curve was drawn by calculating the experimental data. The energy absorption efficiency-stress curve $(E-\sigma)$ was obtained through calculation. The energy absorption efficiency formula ${ }^{31}$ is as follows:

$$
E=\frac{\int_{0}^{\varepsilon} \sigma(\varepsilon) \mathrm{d} \varepsilon}{\sigma(\varepsilon)}
$$

Here, $E$ is the energy absorption efficiency corresponding to strain $\varepsilon$ and $\sigma(\varepsilon)$ is the stress corresponding to strain $\varepsilon$.

\subsection{Micro-characterization of starch and composites}

2.5.1 X-ray diffraction experiment. The different starch samples were dried in a vacuum oven at $85^{\circ} \mathrm{C}$ for $15 \mathrm{~h}$ to obtain anhydrous starch, which was ground using an agate mortar and then run through a 200-mesh sieve. The compacted sample was flat and its surface was parallel to the glass frame. The assay was performed at room temperature by using Ni-filtered $\mathrm{Cu}$ radiation and a curved graphite crystal monochromator. The slit system was DS/RS/SS $=1^{\circ} / 0.16 \mathrm{~mm} / 1^{\circ}$. The angle interval of $5-$ $65^{\circ}$ was analyzed at $5^{\circ} \mathrm{min}^{-1}$.

2.5.2 Infrared spectrum analysis. Anhydrous starch $(5 \mathrm{mg})$ was mixed with $\mathrm{KBr}(150 \mathrm{mg})$ and milled thoroughly to reach a particle diameter of $<2.5 \mu \mathrm{m}$. The mixtures were compressed into pellets under approximately 10-12 MPa and then analyzed using a VERTEX-70 Fourier transform infrared (FTIR) spectrometer. The spectra were recorded at a resolution of $2 \mathrm{~cm}^{-1}$ in the range of $400-4000 \mathrm{~cm}^{-1}$.

2.5.3 Scanning electron microscopy (SEM) of the composites. The spatial structure of starch-based composites was investigated under a scanning electron microscope (FEG250) at an accelerating voltage of $10 \mathrm{kV}$. Prior to SEM, all the samples were mounted on a piece of aluminum by using a carbon ribbon and sputtered on the surface to produce a conductive sample.

\section{Results and discussion}

\subsection{Waterproof property analysis of the composites}

Fig. 3 shows the water absorption of the composites with different masses of PTS as the waterproof additive. The waterproof property of the composites improved at a low water absorption value. ${ }^{32}$ After six days of the experiment, the water absorption values reached $49.1 \%, 31.2 \%, 19.6 \%, 17.1 \%$, and $23 \%$. As shown in Fig. 3, the water absorption value of the composite without PTS (PTS-0) is significantly higher than that of the others, indicating that the addition of PTS can effectively enhance the waterproof property of the composites. However, with the increase in PTS, the water absorption initially decreased and then increased, thereby indicating that the

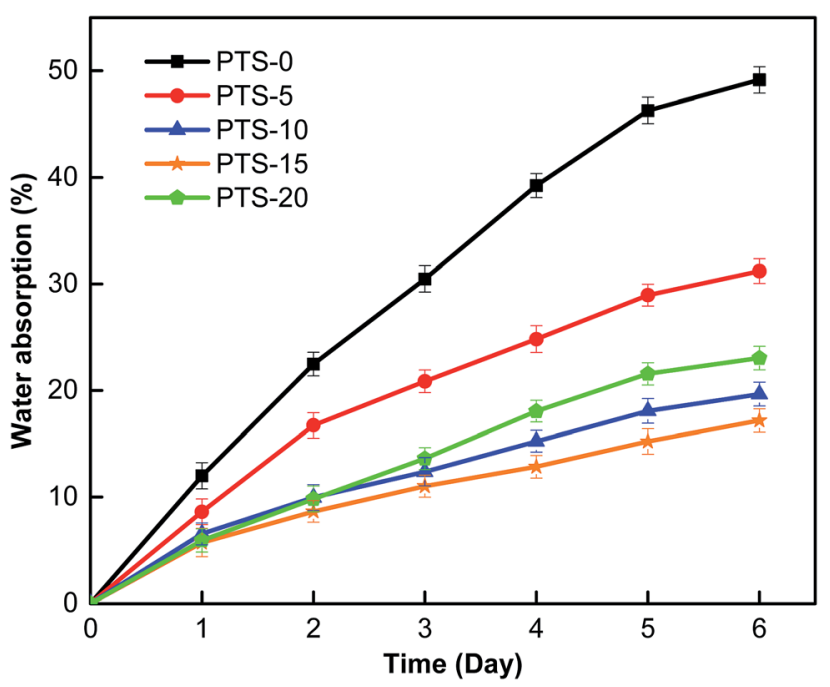

Fig. 3 Water absorption of the composites with different masses of PTS. 
waterproof property of the composite initially increased and then decreased. Moreover, PTS-15 exhibited optimal waterproof property.

The PTS molecules contain main chains consisting of $\mathrm{Si}-\mathrm{O}-$ $\mathrm{Si}$ and side chains composed of organic groups. A layer of nonpolar organic groups exists outside the main chain of the PTS molecules, resulting in the compound's good hydrophobicity. In the composite preparation, with the increase in temperature, PTS tightly combined with the $-\mathrm{OH}$ group in starch, and such a condition not only prevented the formation of intermolecular hydrogen bonds between starch and the fiber but also formed a hydrophobic film with low surface tension on the surface of starch and the fiber molecules. Water molecules could not penetrate the composite, resulting in excellent waterproof property. With the addition of PTS (PTS-5-PTS-15), the waterproof film on the starch and fiber molecule surfaces became increasingly dense. However, when the mass of PTS reached a certain level (PTS-20), the PTS molecules combined, thereby decreasing the waterproof property. However, the waterproof property was still better than that observed without PTS (PTS-0).

Contact angle refers to the tangent line at the intersection of air, liquid, and solid at the air-liquid interface. This tangent line, which is a measure of wettability, features an angle $\theta$ between the liquid and the solid-liquid boundary. The contact

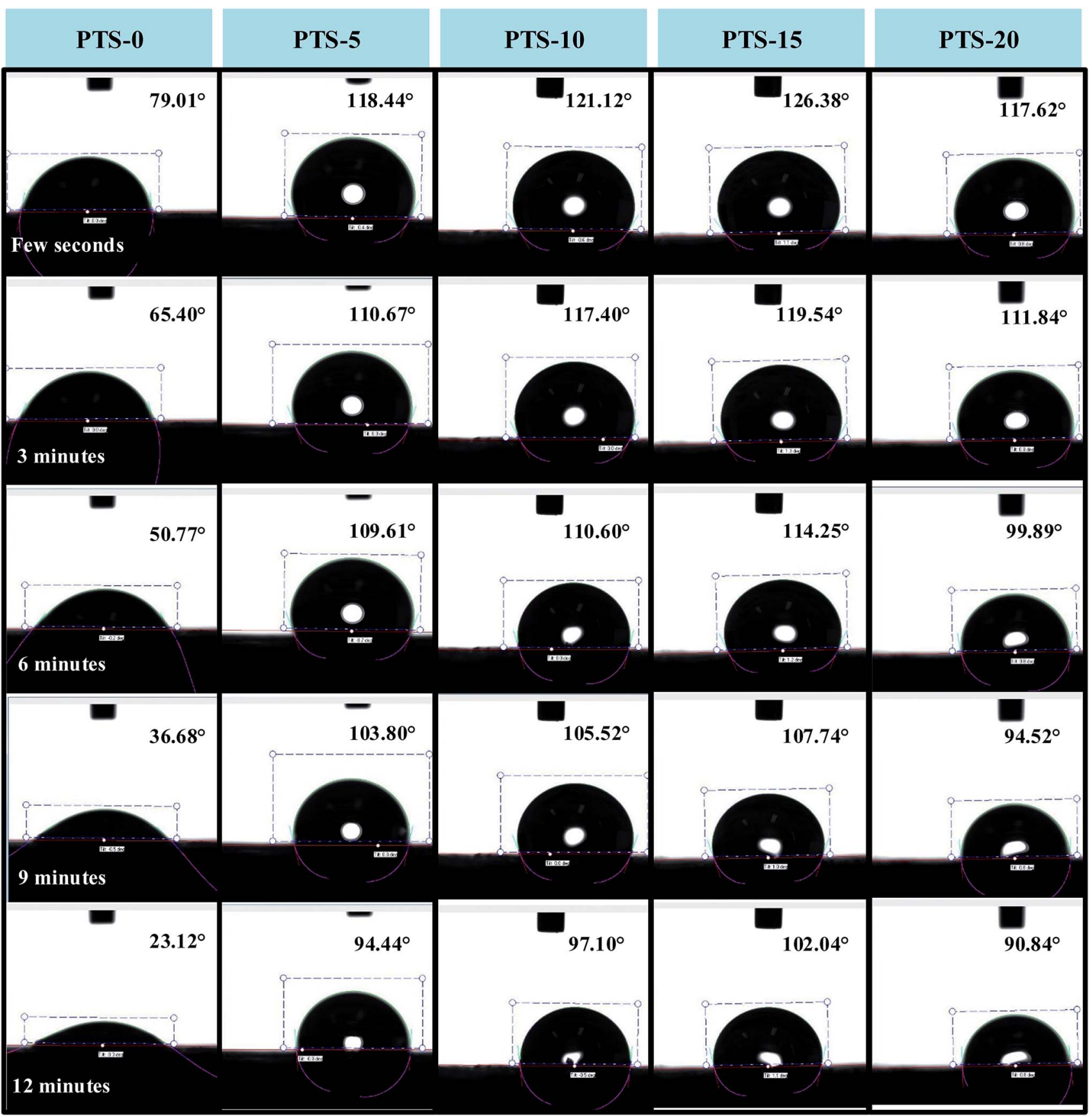

Fig. 4 Water contact angles within $12 \mathrm{~min}$. 
angle of water on the composite surface is an important parameter to measure the wettability of water on the composite surface. When $\theta<65^{\circ}$, the composite surface is hydrophilic; when $\theta>65^{\circ}$, the composite surface exhibits waterproof property. Thus, the waterproof property of the composite surface will improve with the increase in the water contact angle $\theta .^{33}$

Fig. 4 displays the water contact angle of the composites with different masses of PTS within $12 \mathrm{~min}$. The results of contact angle are shown in the upper right corner of each image. The contact angle of the composite without PTS (PTS-0) was obviously less than those of the other composites, which indicated that the addition of PTS can improve the waterproof property of the composites. After $3 \mathrm{~min}$, the contact angle of PTS-0 was less than $65^{\circ}$, which means that it became hydrophilic. However, the contact angles of the other four composites were still more than $65^{\circ}$ within $12 \mathrm{~min}$, which proved that the composites with PTS have great hydrophobicity. PTS-15 presented the largest water contact angle, confirming that this composite possessed the best waterproof property (Fig. 3).

Drop absorption time is used to represent the time from the contact between the water droplet and the composite surface to complete absorption by the composite. A longer water drop absorption time indicates improved waterproof property of the composites. $^{34}$

Table 2 provides the data of the drop absorption time and the differences. The table shows that the addition of PTS extended the drop absorption time. PTS-15 exhibited the longest drop absorption time $(3378 \pm 50 \mathrm{~s})$, confirming the conclusions in Fig. 3 and 4.

\subsection{Mechanical property analysis}

Fig. 5 shows the energy absorption efficiency of the composites with different masses of PTS. The cushioning property of composites is generally characterized by the energy absorption efficiency. High energy absorption efficiency implies improved cushioning properties of the composites. ${ }^{35}$

As shown in Fig. 5, with the increase in stress, the energy absorption efficiency of the composites with different masses of PTS rapidly increases and then decreases slowly. The maximum energy absorption efficiency values totaled $23.89 \%$ (PTS-0), $24.47 \%$ (PTS-5), 24.64\% (PTS-10), 25.16\% (PTS-15), and $23.15 \%$ (PTS-20). The energy absorption efficiencies of the composites differed with the addition of different masses of PTS, confirming that the addition of PTS can affect the cushioning property of the composites. PTS-15 showed the best cushioning property among the composites.

Table 2 Waterproof index of the composites

\begin{tabular}{lll}
\hline Sample & PTS & $\begin{array}{l}\text { Drop absorption } \\
\text { time }\end{array}$ \\
\hline PTS-0 & $0 \mathrm{~g}$ & $1044 \pm 70 \mathrm{~s}$ \\
PTS-5 & $5 \mathrm{~g}$ & $3088 \pm 65 \mathrm{~s}$ \\
PTS-10 & $10 \mathrm{~g}$ & $3166 \pm 55 \mathrm{~s}$ \\
PTS-15 & $15 \mathrm{~g}$ & $3378 \pm 50 \mathrm{~s}$ \\
PTS-20 & $20 \mathrm{~g}$ & $2774 \pm 75 \mathrm{~s}$
\end{tabular}

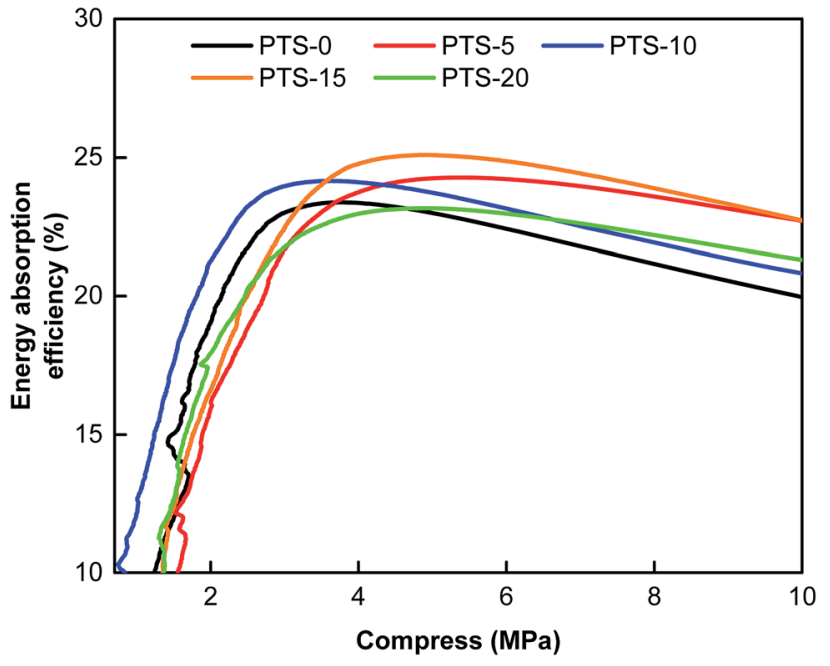

Fig. 5 Energy absorption efficiency of composites with different masses of PTS.

Four groups of samples were prepared, with each group consisting of five samples from PTS-0 to PTS-20. The composites were placed in a test machine at a constant temperature $\left(30^{\circ} \mathrm{C}\right)$ and relative humidity $(\mathrm{RH})(65 \%)$ for six days (the experimental conditions were the same as those given in Section 2.3.1). The tensile property test was conducted per group every two days. The test results are shown in Fig. 6.

Fig. 6 shows that the rates of change in the tensile properties of PTS-0, PTS-5, PTS-10, PTS-15, and PTS-20 reach 56.6\%, $15.9 \%, 15.6 \%, 5.3 \%$, and $18.5 \%$, respectively. Fig. 6 also shows that the rate of change in the tensile property of PTS-0 is larger than that of the others and that of PTS-15 is the smallest among the five samples. Thus, the addition of PTS can effectively prevent the degradation of the mechanical properties of the composites after absorbing water.

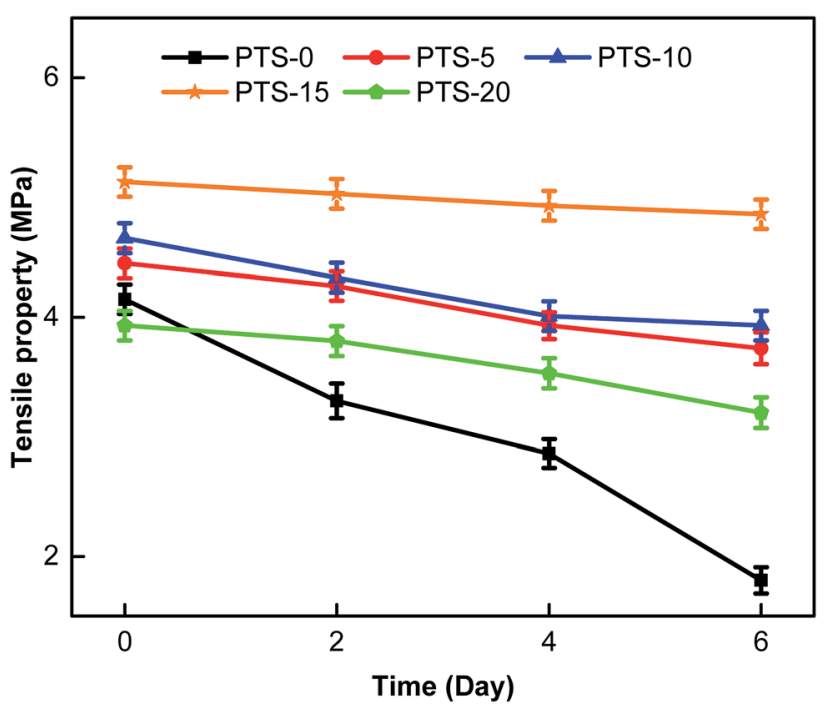

Fig. 6 Tensile properties of the composites under different humidification times. 


\subsection{Microscopic mechanism analysis}

We tested the FT-IR spectra of starch slurry to further explore the reasons for changes in the waterproof and mechanical properties of the composites.

In the IR spectra of the starch-fiber composites, the absorption peak associated with the stretching oscillation of the $\mathrm{O}-\mathrm{H}$ (hydroxyl) group is found at approximately 3645$3300 \mathrm{~cm}^{-1}$. The hydrogen-bonding effect changed the stretching vibration frequency of the $\mathrm{O}-\mathrm{H}$ (hydroxyl) group in the infrared spectrum, including the shift in the absorption peak towards low frequency. Thus, a low wavenumber indicates a strong hydrogen bond..$^{36}$ Fig. 7 shows that the FT-IR spectra of the slurry in PTS-0 and PTS-15 are in the range of 4000$1500 \mathrm{~cm}^{-1}$. As shown in Fig. 7, the peak value for $\mathrm{O}-\mathrm{H}$ absorption of the slurry prepared using $0 \mathrm{~g}$ PTS is $3398.479 \mathrm{~cm}^{-1}$. The peak value for $\mathrm{O}-\mathrm{H}$ absorption of the slurry prepared using PTS-15 shifted to a low frequency at $3336.759 \mathrm{~cm}^{-1}$, revealing that new hydrogen bonds were formed between PTS and starch. Other results showed that the formation of hydroxyl functional groups was related to the absorption peak that shifted to a lower wavenumber. ${ }^{37,38}$ The spectra in Fig. 7 evidently reveal the hydrogen bonds between starch and PTS. The formation of new hydrogen bonds proved the differences in the mechanical properties of the composites.

Fig. 8 shows the molecular model for the combination of PTS and starch through new hydrogen bonds. When glycerin and glycol were added to starch, the starch microstructure changed and the compatibility or homogeneity of the blending composites improved. ${ }^{39}$

In physics, plasticizers can dissolve the crystal structure of starch granules. Glycerin provides mobility to the plasticizer system, endowing it with the capacity to penetrate and diffuse through the starch granules. ${ }^{40}$

In chemistry, glycerin and glycol as plasticizers can be efficient in disrupting the chemical bonds holding the starch molecules together. They expose the hydrogen and oxygen atoms in starch to form new hydrogen bonds with PTS, as shown in Fig. 8.

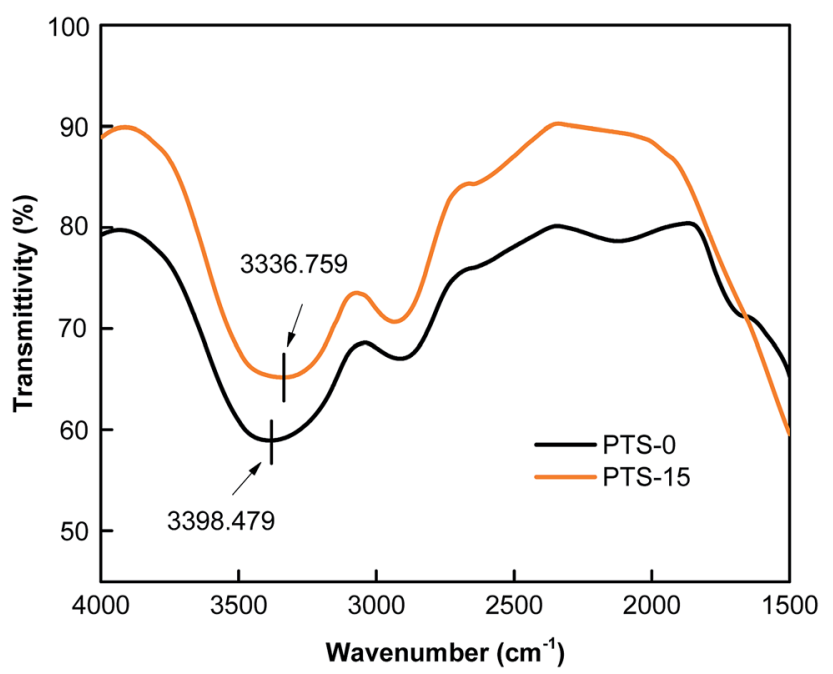

Fig. 7 FT-IR spectra $\left(4000-1500 \mathrm{~cm}^{-1}\right)$ of PTS-0 and PTS-15.

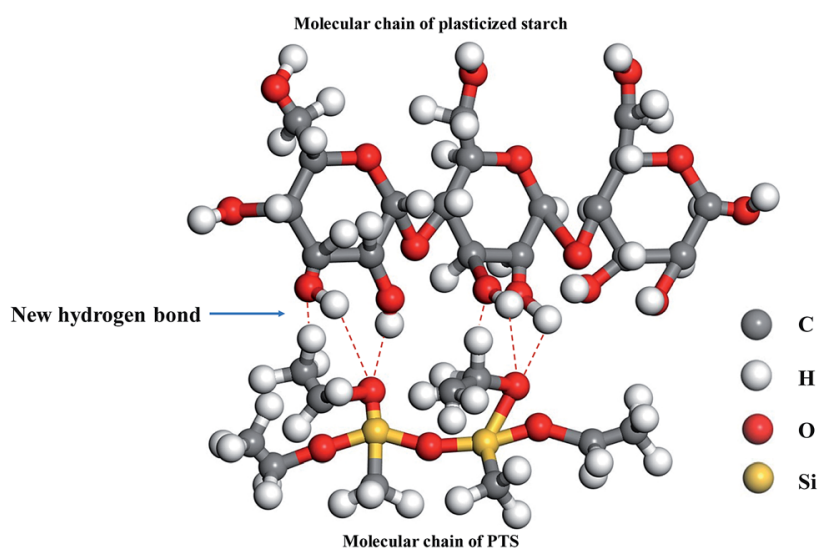

Fig. 8 Molecular model of PTS and starch combination through new hydrogen bonds.

Fig. 9 shows the FTIR spectra of the composites with different masses of PTS in the range of $1500-600 \mathrm{~cm}^{-1}$. Compared with PTS-0, the other composites showed new absorption peaks at 1024.172 and $877.586 \mathrm{~cm}^{-1}$. The vibration frequency table of organic groups indicates that the composites form hydrophobic groups, namely, $\mathrm{Si}-\mathrm{C}, \mathrm{Si}-\mathrm{OH}$, and $\mathrm{Si}-\mathrm{O}-\mathrm{Si}$, which are observed at 877.586, 900.732, and $1024.172 \mathrm{~cm}^{-1},{ }^{41}$ respectively, thus explaining the waterproof characteristics of the composites with PTS.

We tested starch with different masses of PTS using X-ray diffraction to explore the relationship between the microscopic mechanism and the mechanical properties of the composites. Starch molecules comprise crystallization and amorphous zones. The size of the crystallization zone can be expressed by crystallinity. The degree of crystallinity, which is the percentage of crystalline regions with respect to the total material, is a valuable parameter to consider because it influences the physical, mechanical, and technological properties of materials. ${ }^{42}$ When the crystallization zone is small, more free branched chains are present in the starch molecules; these chains can aid in the

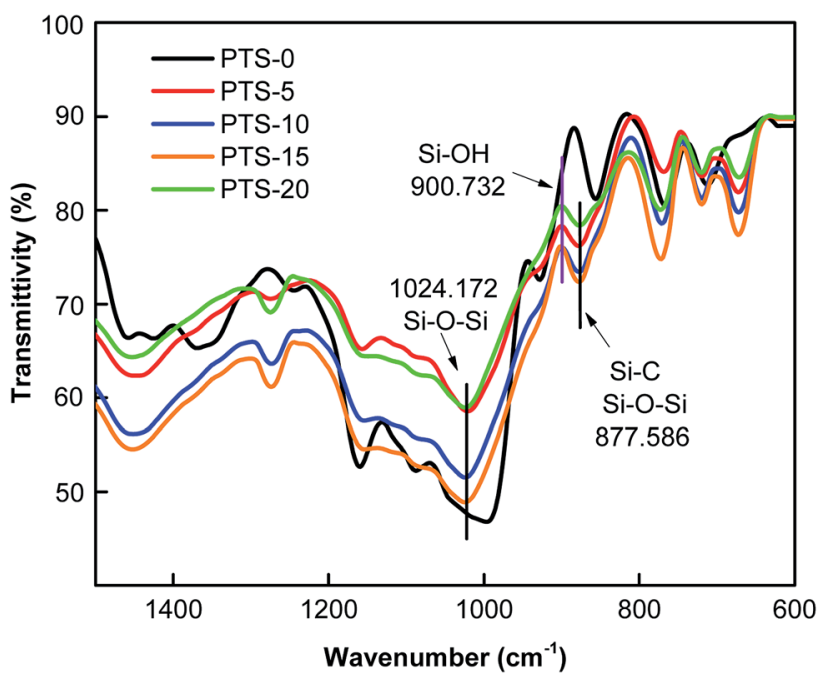

Fig. 9 FTIR spectra $\left(600-1500 \mathrm{~cm}^{-1}\right)$. 


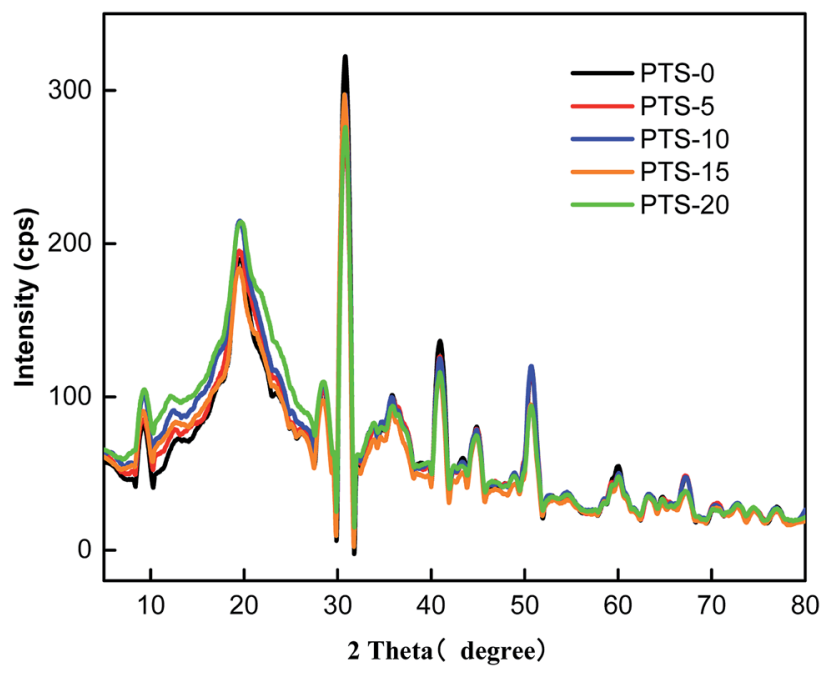

Fig. $10 \mathrm{X}$-ray diffraction patterns of starch with different masses of PTS.

combination of starch and fiber molecules, thereby leading to better mechanical properties of the composites.

Fig. 10 illustrates the test results. The analysis results showed that the crystallization, peak shape, and position of the five groups were almost consistent. Of note, TPS is an amorphous substance. Fig. 9 shows that the addition of PTS caused no effect on the crystalline structure of starch molecules. In other words, the change in the mechanical properties is independent of the crystalline structure.

\subsection{Micromorphology analysis}

We conducted SEM analysis of the composites with different masses of PTS to further investigate the related micromechanism; the results are shown in Fig. 11.

An open cell microstructure is related to the mechanical properties of composites. The wall of an open cell structure is used as the supporting structure of the composites. Therefore, the supporting structure and the mechanical properties of the composites will only improve under large numbers of open cell structures in the composites and their even distribution.

As shown in Fig. 11, there are four microscopic open cell structure images of the composites with different masses of PTS. The open cell structures become increasingly dense, as shown in Fig. 11(a)-(c). However, the open cell structure becomes larger, as shown in Fig. 11(d). This phenomenon was consistent with the mechanical properties of the composites with different masses of PTS. This phenomenon is attributed to the following reasons: (1) the addition of PTS can combine the starch and fiber to form more hydrogen bonds, thereby increasing the compatibility between the starch and fiber molecules, thus resulting in more uniform distribution; (2) the addition of PTS as a liquid would increase the rheological properties of the starch slurry. ${ }^{43}$ Thus, the composite flowed
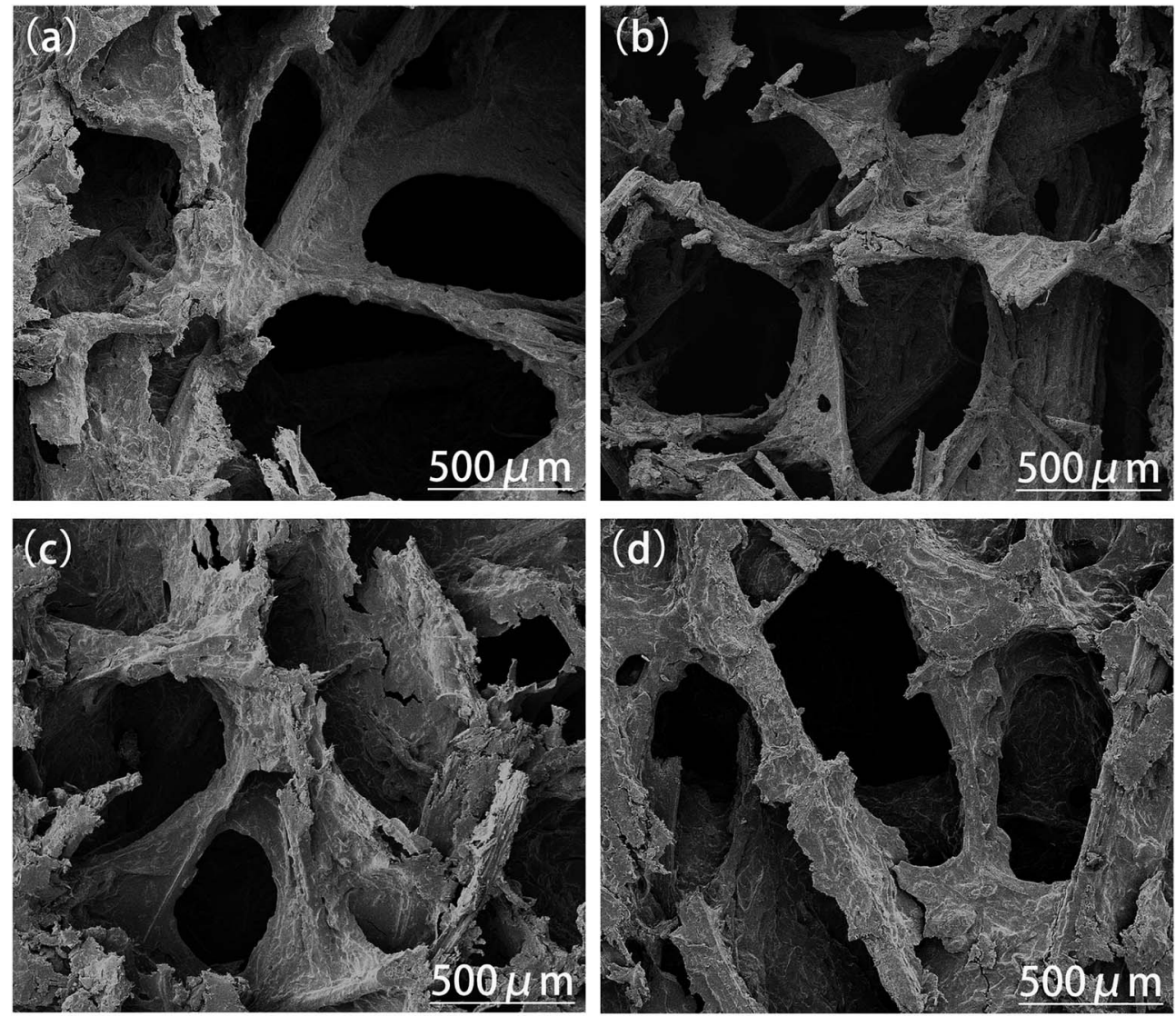

Fig. 11 SEM images of the composites with different masses of PTS: (a) PTS-5; (b) PTS-10; (c) PTS-15; (d) PTS-20. 
more easily in the mold to result in even distribution. However, when PTS was added in a certain amount, the concentration of the starch slurry decreased and the internal structure of the composite was affected; thus, the microstructure deteriorated.

\section{Conclusion}

Novel biodegradable composites with open cell structures were prepared through thermo-cavity foam molding using starch and fiber as the main raw materials. To overcome the disadvantage of the water sensitivity of the resulting composites, PTS was added as a waterproof agent.

The waterproof property initially increased and then decreased with the increase in PTS. Moreover, the PTS-15 composite exhibited optimal waterproof property, achieving a contact angle of 126.38 and drop absorption time of $3378 \pm$ $50 \mathrm{~s}$, which improved by $59.9 \%$ and $223.5 \%$, respectively, compared with those of PTS-0.

The addition of PTS effectively prevented the degradation of the mechanical properties of the composites after water absorption. The rates of change in the tensile properties of PTS15 and PTS-0 composites reached 5.3\% and 56.6\%, respectively.

The peak value for $\mathrm{O}-\mathrm{H}$ absorption of the PTS-15 composites shifted to a low frequency from $3398.479 \mathrm{~cm}^{-1}$ to $3336.759 \mathrm{~cm}^{-1}$, which revealed the formation of new hydrogen bonds in the resulting composites. The $\mathrm{Si}-\mathrm{O}-\mathrm{Si}, \mathrm{Si}-\mathrm{C}$, and $\mathrm{Si}-\mathrm{OH}$ hydrophobic groups were also detected in the FTIR spectra of the composites, thereby explaining the changes in the waterproof properties of the composites. The SEM images show that on increasing the PTS content, the open cell structure of the composites initially becomes dense and then loosens. In addition, the PTS-15 composite exhibited an optimal uniform open cell structure.

\section{Conflicts of interest}

There are no conflicts of interest to declare.

\section{Acknowledgements}

This work was financially supported by National Natural Science Foundation of China (No. 51775318), and the Interdisciplinary Cultivation Project of Shandong University (No. 2018JC043). We would like to thank our colleagues from Shandong University.

\section{References}

$1 \mathrm{~S}$. Adak and R. Banerjee, A green approach for starch modification: esterification by lipase and novel imidazolium surfactant, Carbohydr. Polym., 2016, 150, 359368.

2 S. Chinaglia, M. Tosin and F. Degli-Innocenti, Biodegradation rate of biodegradable plastics at molecular level, Polym. Degrad. Stab., 2018, 147, 237-244.

3 G. Francucci and E. Rodriguez, Processing of plant fiber composites by liquid molding techniques: an overview, Polym. Compos., 2014, 37(3), 718-733.
4 S. Chen, F. Y. Li and J. F. Li, Effects of single-modification/ cross-modification of starch on the mechanical properties of new biodegradable composites, RSC Adv., 2018, 8(22), 12400-12408.

5 O. Faruk, A. K. Bledzki and H. P. Fink, Biocomposites reinforced with natural fibers: 2000-2010, Prog. Polym. Sci., 2012, 37(11), 1552-1596.

6 C. W. Zhang, F. Y. Li, J. F. Li, L. M. Wang, Q. Xie, J. Xu and S. Chen, A new biodegradable composite with open cell by combining modified starch and plant fibers, Mater. Des., 2017, 120, 222-229.

7 L. Mao, S. Imam, S. Gordon, P. Cinelli and E. Chiellini, Extruded cornstarchglycerolpolyvinyl alcohol blends: mechanical properties, morphology, and biodegradability, J. Polym. Environ., 2000, 8(4), 205-211.

8 E. Šárka, Z. Kruliš, J. Kotek, L. Růžek, K. Vořek, J. Kolček and O. Ekrt, Composites containing acetylated wheat B-starch for agriculture applications, Plant, Soil Environ., 2012, 58, 354359.

9 N. Wang, J. Yu, P. R. Chang and X. Ma, Influence of formamide and water on the properties of thermoplastic starch/poly(lactic acid) blends, Carbohydr. Polym., 2008, 71(1), 109-118.

10 J. Castaño, S. RodríguezLlamazares, C. Carrasco and R. Bouza, Physical, chemical and mechanical properties of pehuen cellulosic husk and its pehuenstarch based composites, Carbohydr. Polym., 2012, 90(4), 1550-1556.

11 Q. Xie, F. Li, J. Li, L. Wang, Y. Li and C. Zhang, A new biodegradable sisal fiber-starch packing composite with nest structure, Carbohydr. Polym., 2018, 189, 56-64.

12 S. Adak and R. Banerjee, A green approach for starch modification: esterification by lipase and novel imidazolium surfactant, Carbohydr. Polym., 2016, 150, 359368.

13 C. S. Schmitz, K. N. D. Simas, K. Santos, J. J. João and E. R. Amante, Cassava starch functional properties by etherification - hydroxypropylation, Int. J. Food Sci. Technol., 2010, 41(6), 681-687.

14 Y. Li, R. De Vries, T. Slaghek, J. Timmermans, M. A. Cohen Stuart and W. Norde, Preparation and characterization of oxidized starch polymer microgels for encapsulation and controlled release of functional ingredients, Biomacromolecules, 2009, 10(7), 1931-1938.

15 J. Meimoun, V. Wiatz, R. Saint-Loup, J. Parcq, A. Favrelle, F. Bonnet, et al., Modification of starch by graft copolymerization, Starch/Staerke, 2017, 70(1-2), 1600351.

16 H. Schmitt, A. Guidez, K. Prashantha, J. Soulestin, M. F. Lacrampe and P. Krawczak, Studies on the effect of storage time and plasticizers on the structural variations in thermoplastic starch, Carbohydr. Polym., 2015, 115, 364-372.

17 C. W. Zhang, F. Y. Li, J. F. Li, J. Xu, Q. Xie, S. Chen, et al., Research on rheological behavior of biobased composite slurry composed of sisal fiber and thermoplastic oxidized starch, J. Biobased Mater. Bioenergy, 2017, 11(2), 119-124.

18 C. W. Zhang, F. Y. Li, J. F. Li, Y. L. Li, J. Xu, Q. Xie, et al., Novel treatments for compatibility of plant fiber and starch by 
forming new hydrogen bonds, J. Cleaner Prod., 2018, 185, 357-365.

19 Y. Jiugao, W. Ning and M. Xiaofei, The effects of citric acid on the properties of thermoplastic starch plasticized by glycerol, Starch/Staerke, 2005, 57(10), 494-504.

20 A. Cova, A. J. Sandoval, V. Balsamo and A. J. Müller, The effect of hydrophobic modifications on the adsorption isotherms of cassava starch, Carbohydr. Polym., 2010, 81(3), 660-667.

21 X. Ma, P. R. Chang, J. Yu and M. Stumborg, Properties of biodegradable citric acid-modified granular starch/ thermoplastic pea starch composites, Carbohydr. Polym., 2009, 75(1), 1-8.

22 W. Mingcun, N. Yi, H. Weijian and Z. Tong, Oligosilazane cured by moisture as fluorine-free hydrophobic coating for waterproof polymer-matrix composite materials, J. Coat. Technol. Res., 2018, 15(6), 1251-1258.

23 Y. Han, S. O. Manolach, F. Denes and R. M. Rowell, Cold plasma treatment on starch foam reinforced with wood fiber for its surface hydrophobicity, Carbohydr. Polym., 2011, 86(2), 1031-1037.

24 E. Lee, H. Zhang, J. K. Jackson, C. J. Lim and M. Chiao, Janus films with stretchable and waterproof properties for wound care and drug delivery applications, $R S C A d v$., 2016, 6(83), 79900-79909.

25 J. Gong, Z. Duan, K. Sun and M. Xiao, Waterproof properties of thermal insulation mortar containing vitrified microsphere, Constr. Build. Mater., 2016, 123, 274-280.

26 X. Lu, Y. Sun, Z. Chen and Y. Gao, A multi-functional textile that combines self-cleaning, water-proofing and $\mathrm{VO}_{2}$-based temperature-responsive thermoregulating, Sol. Energy Mater. Sol. Cells, 2017, 159, 102-111.

27 Z. Chuan-Wei, L. Fang-Yi, L. Jian-Feng, X. Qi, X. Jie, G. An-Fu, et al., Effect of crystal structure and hydrogen bond of thermoplastic oxidized starch on manufacturing of starchbased biomass composite, International Journal of Precision Engineering and Manufacturing-Green Technology, 2018, 5(3), 435-440.

28 M. F. Huang, J. G. Yu and X. F. Ma, Studies on the properties of montmorillonite-reinforced thermoplastic starch composites, Polymer, 2004, 45(20), 7017-7023.

29 G. Mchale, N. J. Shirtcliffe and M. I. Newton, Contact-angle hysteresis on super-hydrophobic surfaces, Langmuir, 2004, 20(23), 10146-10149.

30 M. Bente, G. Avramidis, S. Förster, E. G. Rohwer and W. Viöl, Wood surface modification in dielectric barrier discharges at atmospheric pressure for creating water repellent characteristics, Holz Roh- Werkst., 2004, 62(3), 157-163.

$31 \mathrm{~J}$. Miltz and G. Gruenbaum, Evaluation of cushioning properties of plastic foams from compressive measurements, Polym. Eng. Sci., 2010, 21(15), 1010-1014.

$32 \mathrm{M}$. Bootklad and K. Kaewtatip, Biodegradation of thermoplastic starch/eggshell powder composites, Carbohydr. Polym., 2013, 97(2), 315-320.

33 E. A. Vogler, Structure and Reactivity of Water at Biomaterial Surfaces, Adv. Colloid Interface Sci., 1998, 74(1-3), 69-117.

34 S. M. Mukhopadhyay, P. Joshi, S. Datta, J. G. Zhao and P. France, Plasma assisted hydrophobic coatings on porous materials: influence of plasma parameters, J. Phys. D: Appl. Phys., 2002, 35(16), 1927-1933.

35 Z. W. Wang and X. F. Li, Effect of strain rate on cushioning properties of molded pulp products, Mater. Des., 2014, 57(5), 598-607.

36 A. Finch, Chemical applications of far infrared spectroscopy, Academic Press, 1970, .

37 K. Kaewtatip and J. Thongmee, Effect of kraft lignin and esterified lignin on the properties of thermoplastic starch, Mater. Des., 2013, 49, 701-704.

38 S. Sultana, N. Nafsin, N. Hasan, M. Hasan, et al., Improvement of physico-mechanical properties of coirpolypropylene;biocomposites by fiber chemical treatment, Mater. Des., 2013, 52(52), 251-257.

39 X. S. Wu, Effect of glycerin and starch crosslinking on molecular compatibility of biodegradable poly(lactic acid)starch composites, J. Polym. Environ., 2011, 19(4), 912-917.

40 A. Córdoba, N. Cuéllar, M. González and J. Medina, The plasticizing effect of alginate on the thermoplastic starch/ glycerin blends, Carbohydr. Polym., 2008, 73(3), 409-416.

$41 \mathrm{H}$. Jiang, Z. Zheng and X. Wang, Kinetic study of methyltriethoxysilane (mtes) hydrolysis by ftir spectroscopy under different temperatures and solvents, Vib. Spectrosc., 2008, 46(1), 1-7.

42 A. Lopez-Rubio, B. M. Flanagan, E. P. Gilbert and M. J. Gidley, A novel approach for calculating starch crystallinity and its correlation with double helix content: a combined xrd and nmr study, Biopolymers, 2008, 89(9), 761-768.

$43 \mathrm{~S} . \mathrm{Xu}, \mathrm{F}$. C. Jin, J. J. Xiu, et al., Starch and Plant Fiber Reinforced Biodegradable Composites with Open Cell Structures, J. Biobased Mater. Bioenergy, 2019, 13(No. 4), 438-445. 